Marketing in Asia Group

Asian Journal of Business Research

Volume 9 Issue 3, 2019

ISSN 2463-4522 e-ISSN 1778-8933

DOI: $10.14707 / a j b r .190068$

\title{
A Study into the Development Strategy of Qianhai Cooperation Zone based on Non-cooperative Game
}

\author{
Ka-Yin Chau \\ Faculty of International Tourism and Management, City University of Macau, China
}

Shi-Zheng Huang

School of Economics and Management, Guangdong University of Petrochemical Technology, Maoming, China

Hua-Wen Shen

Faculty of International Tourism and Management, City University of Macau, China

Man Lai Cheung

Faculty of International Tourism and Management, City University of Macau, China

Hai-Liang Zeng

School of Economics and Management, Guangdong University of Petrochemical Technology, Maoming, China

Faculty of International Tourism and Management, City University of Macau, China

\begin{abstract}
The Qianhai Shenzhen-Hong Kong Modern Service Industry Cooperation Zone, as another pilot project of reforming and innovation of Shenzhen Special Economic Zone, will emphasize Shenzhen - Hong Kong regional cooperation. But the cooperation and competition among governments are of public choice, and the development of Qianhai is related to the decisions made or to be made by the Central Government and local governments of Hong Kong, Guangdong and Shenzhen. This study explored and analysed the strategy selection of Qianhai Cooperation Zone by Hong Kong and Shenzhen governments using game theory. We believed that the goal of maximizing local benefits on the part of local governments, as the local interest protectors, will inevitably result in problems such as local protectionism, market segmentation, and synergetic development and so on. More importantly, the coordination by the Central Government is a valid channel shifting from the Prisoner's Dilemma to the Cooperative Game for the development of Qianhai Cooperation Zone, thus providing references for the study on the development strategy of Cooperation Zone.
\end{abstract}

Keywords: Qianhai Cooperation Zone, Shenzhen-Hong Kong Cooperation, Prisoner's Dilemma, Intergovernmental Relations

Publication Details: Received 22 Aug 2019; Revised 1 Dec 2019; Accepted 10 Dec 2019 


\section{Introduction}

The Qianhai Shenzhen-Hong Kong Modern Service Industry Cooperation Zone (hereafter referred to as Qianhai or Qianhai Cooperation Zone) is a newly developed economic zone in Shenzhen, the city neighbouring Hong Kong, it is an important carrier in the Guangdong-Hong Kong-Macao Greater Bay Area. On one side, the Qianhai Zone emphasizes the industries like pillar industries in Hong Kong, which leads to worry about "Emptiness" and "Prophetization" in Hong Kong. On the other side, the competitive strength and driving force of Qianhai Cooperation Zone are based on Shenzhen-Hong Kong Cooperation, and Hong Kong's participation is indispensable for the development of Qianhai.

In general, Hong Kong is serving as a bridge for the Mainland China to connect to the international market, has played an important role in the reform and opening-up of China. But this role as "window and bridge" has been gradually weakened after the enrolment of China in the World Trade Organization (WTO) and the Closer Economic Partnership Arrangement (CEPA). In the last 30 years, Hong Kong and Shenzhen have stepped out of the mode of "Shops in Front and Factories Behind", and gradually formed their industrial division of mutual complementation and staggered development. Hong Kong's international competitiveness is largely weakened by serious lack of land resources, rising property prices and rising price index (Lo et al., 2001; Liu, 2003; Li, Ding \& Zhu., 2011; Gu, Cao \& Yang., 2018; He et al.2019). The promulgation of the CEPA further strengthened the economic connection between Hong Kong and the Mainland China, and consolidated Hong Kong's role as the economic centre of the Pearl River Delta and Shenzhen as the subcentre, laying the policy foundation of Shenzhen - Hong Kong integration and clearing Shenzhen's route selection of constructing itself to be an international city (Mo, 1999; Wei, 2007; Tan, 2008; Huang et al.2018). Currently, Hong Kong and Shenzhen are facing the problems and challenges of population, finance, technology and logistics, etc. Hong Kong can expand its economic strength by the extension and deepening of the Qianhai Cooperation Zone. Furthermore, Shenzhen is a "young" city that needs to be supported by Hong Kong's international experience, trade platform, talents and capital. Since the Qianhai Cooperation Zone is "a special zone in the special zones", Hong Kong and Shenzhen should grasp the historical opportunities to innovate their cooperation mode and deepen operation, thus creating a common prosperity in Hong Kong and Shenzhen.

The integration between Shenzhen-Hong Kong is imperative, but cooperation would unavoidably result in competition and splitting-flow. Based on their study, Schellekens and Philip (2002) found that Shenzhen - Hong Kong integration had little influence on deflation in Hong Kong. Song Enrong (2003) argued that the positive influences of integration on Hong Kong far exceed its negative influences. The strategy of protecting local benefits, in addition to the system of transfer and promotion resulting from achievements, is a core issue for local governments (Zhou, 2004; Zhu, 2005; Huang, Tsai \& Cheng, 2017; Gu, Cao \& Yang, 2018). The goal of seeking maximum local benefits on the part of local governments of Shenzhen and Hong Kong, as the protectors of local benefit, will inevitably result in problems such as local protectionism, market segmentation and synergetic development. Therefore, the development of Qianhai mainly relates to two aspects: regional economic development conflicts and cooperation between Hong Kong and Shenzhen. The local 
conflict of interests, which is objectively exists in the regional cooperation, has become an issue to be solved in the synergetic development of Shenzhen and Hong Kong.

As the development of China cooperation zones has just begun, there are few academic study essays in this area. Although prior studies have studied the development of Hong Kong - Shenzhen cooperation (Mo, 1999; Lo et al., 2001; Liu, 2003; Wei, 2007; Tan, 2008; Li, Ding \& Zhu., 2011; Gu, Cao \& Yang, 2018; Huang et al., 2018), they mainly focus on planning layout, legal systems, industrial division, cooperative development mode, etc. There are few researchers have worked on competition decisions on the cooperation zones among the governments. For example, the goal of maximizing local benefits on the part of local governments, as the local interest protectors, will inevitably result in problems such as local protectionism, market segmentation, and synergetic development and so on. The conflict of local interests is an internal demand contradiction existing in regional cooperation, which has become an urgent problem to be solved in the coordinated development of Shenzhen and Hong Kong. In this aspect, the Game Theory provides a framework of strategic actions of individual decision makers, based on which the widely accepted solutions are developed. The Game can solve the decisions of strategies among states, between local governments and the state, and among local governments (Madani, 2010; Huang, Tsai \& Cheng, 2017; Gu, Cao \& Yang., 2018; Chen, Wang \& Huang, 2019). Anderson et al (2012) also used it to make decisions on the infrastructures among governments. Applying Game Theory, this study analysed the competition conflicts and cooperation in the development of Qianhai Cooperation Zone, and conducted a deep analysis of selection of development strategies on the Qianhai Cooperation Zone for the governments. It also analysed the contradictory circumstances arising in the course of regional economic competition and cooperation from another angle of view, and explored and discussed the intergovernmental decision-making acts based on their respective resource strengths. Based on these analyses, we would form a layout for regional economic development, with strengths supplemented, resources shared and market widened, and propose basic ideas for solving problems, thus providing references for study on regional economic cooperation strategies between Hong Kong and Shenzhen.

We will introduce the competition theory among the governments in Part 2, and outline the information about Qianhai Cooperation Zone and raise the issuers of the development about the cooperation zones in Part 3. In Part 4, the development strategies of Hong Kong and Shenzhen as to Qianhai Cooperation Zone will be discussed based on the Game Theory. The last part, as a wrap-up, describes the conclusions and limitations of this study.

\section{Literature Review}

\section{Intergovernmental Relations}

The Intergovernmental Relations refers to the vertically and horizontally staggered relations among the governments, and the relations among the governments of different jurisdictions. Breton (1978) first proposed the concept of "competitive government", in which the horizontal and vertical relations among the governments 
are brought into the competition scope. According to Hayek (1997), the actions of local governments had many strengths that private enterprises have, and the competitions among the local governments can reflect most of the strengths of free development. Herrmann-Pillath (1991) designed an analysis framework of competition among the governments, stating that the competition among the Chinese governments is "tending to federalization quietly". Porter (1979) raised the "Region (Location) Paradox" and argued the region (location) is critical to competition. In addition, Dommel (1991) proposed that there were two key dimensions: competition and cooperation in the horizontal governmental relations.

The essence of the competition in the economic market among local governments is interdependent and the local governments have closely correlated to each other. Fan et al. (1990) analysed the brother competition among the local governments by assuming that local governments represent the overall benefits within the jurisdictions. Shen et al (1990) raised that a local government had a dual identity, subject of economic adjustment and control, and subject of economic benefit, and "duke economy" was caused by over-inclination of the latter. Li (2004) pointed out that the surpassing strategy and system of the Central Government would lead to local protection and market segmentation. Mo (1999) proposed that to develop the Shenzhen - Hong Kong Cooperation, the negotiations between two governments and guidance by the Central Government were both required. According to Zhu and Gu (2005), the benefits of the local governments were classified into two aspects: political benefits and economic benefits. In addition, Zhou (2004) argued that the fundamental reason for the difficulty cooperation among government officials is not mainly determined by local economic benefits, but by the nature of the political promotion game embedded into the economic competition.

\section{Resource-Based View (RBV)}

The Resource-Based View (RBV) has been widely used in the teaching and academic research of strategy management (Penrose, 1959). According to the study on RBV by Barney (1991), etc., resources had four features: value, rarity, inimitable and nonsubstitutable, among which value and rarity are the necessary conditions of creating competitive advantages. The basic differences of the local governments in respect of regional resources and economic foundation and their relations with the Central Government determine that individual governments might have identical and different competitiveness. The RBV theory is also expanded to include external resources. For example, resources can be obtained using external relations to innovate to reduce relevant risks (Lee \& Wong, 2009; Tether, 2002). The development of economy among governments may not only generate economic benefits, but also improve political achievements from the economic development. The development of economy is based on attracting foreign capital, as well as protecting and fostering local market. For this aim, local governments generally adopt both market competition and protection. Currently, the game among Chinese local governments is reflected in the competition among the local governments at the same level within certain jurisdiction, with similar resource advantages and geographical position, equivalent economic strengths, and similar management systems. For this reason, this study only analyses the process of strategy selection for the development of the Qianhai Cooperation Zone between the governments of Hong Kong and Shenzhen based on resource advantages. 


\section{Current Development Status of Qianhai Cooperation Zone}

The cooperation zone, a kind of economic park, is defined as an industrial area designated by a country or region, where policies are implemented to encourage certain industries. In a cooperation zone, according to the regional economic development strategy, the government, a designated agency or an economic development entity implements unified planning, construction, management and operation in respect of overall development, industry orientation, and public infrastructures and so on. Cooperation zones can drive the development of regional economy and urbanization, promote investment and capital introduction, and enhance the competitiveness of regional economy. Based on the approved conditions, they could be classified into national and provincial cooperation zones. National cooperation zones are directly approved by the State Council, which would be largely supported in respect of land, tax income, fiscal and finance, etc. and especially specified with regards to structures, powers and legal systems, etc., and the State Council will make key arrangements regarding examination, and approval and construction of major projects. Since 2009, 16 national cooperation zones have been approved and established in China, of which the Qianhai Cooperation Zone is the smallest.

\section{Figure 1: Qianhai Cooperation Zone Geographic Location Map}

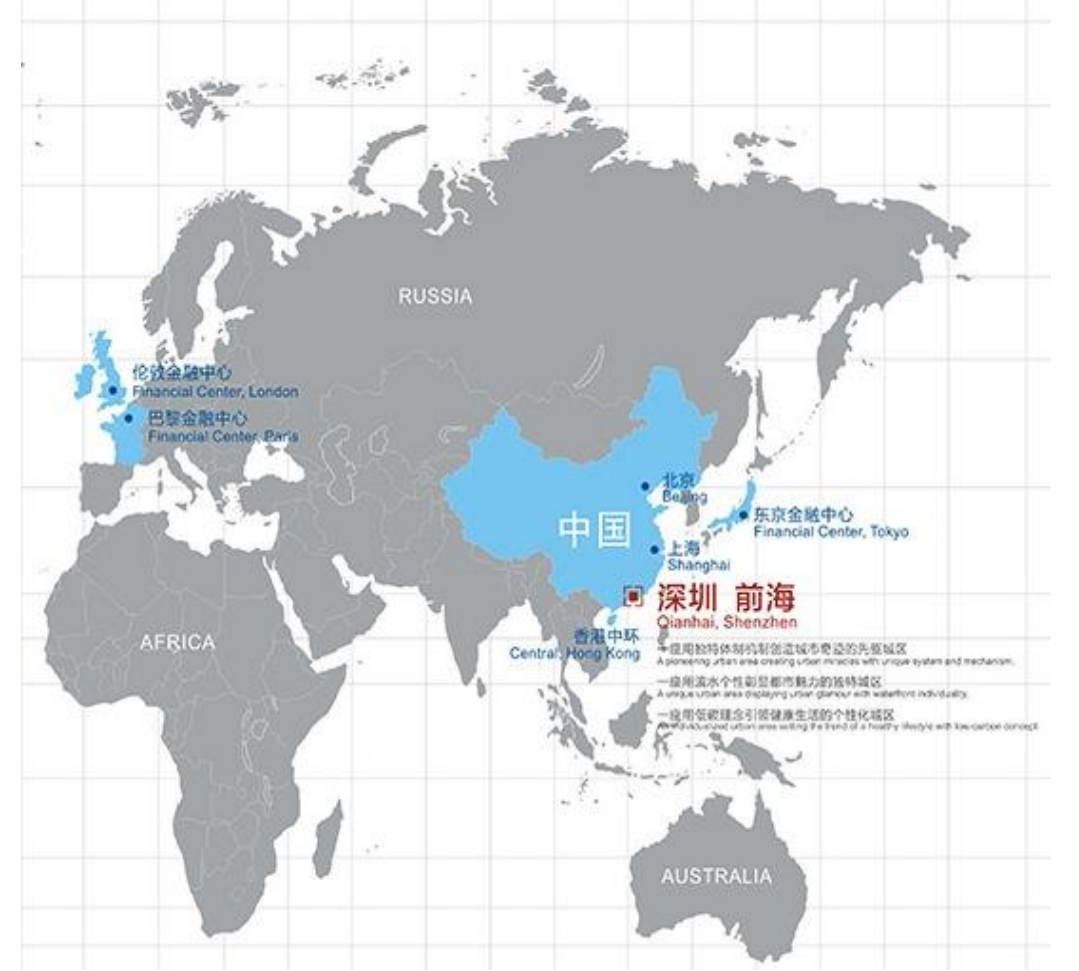

The Qianhai Shenzhen-Hong Kong Modern Service Industry Cooperation Zone, established under approval of the State Council in Aug. 2010, has the administration power of a city specifically designated in the state plan (計畫單列市). It is located on the west of Shekou Peninsula in west Shenzhen, on the eastern bank of the Pearl River Estuary. It is situated in the inter-junction of the economic development principal axis of Pearl River Delta and the coastal function expansion belt, closing to Hong Kong and Macao, with an area of $14.92 \mathrm{~km} 2$ (see Figure 1). It was listed in the outline of national 12th-Five-Year Program in 2011, and upgraded to be the national 
development strategy, and the construction of infrastructure hardware expected to be done in 2020. The function of Qianhai Cooperation Zone is positioned to be a systematic innovation area of modern service industry, a clustered development area of modern service industry, the forerunner area of close cooperation between Hong Kong and the Mainland China, and the leading area of industrial upgrading in the Pearl River Delta. The Qianhai Cooperation Zone emphasize on four industries of finance, modern logistics, information service, S\&T service and other professional service, and implement “first move" policy (先行先試) in the fields of finance, tax income, legal matters, talents, education \& medical treatment and telecom. It is expected to have seven "innovation" advantages, in which the individual income tax rate and corporate income tax rate should lower than Hong Kong. As of December 2018, there were 10,800 registered enterprises with registered capital of RMB1,074.904 billion and total tax payment of RMB10.084 billion.

\section{Current Development Status of Economic Trade in Shenzhen and Hong Kong}

Hong Kong and Shenzhen are both located on the eastern bank of the Pearl River Estuary and are separated from each other only by a river. The former is a hub of increasingly developing East Asia, and international financing, commercial trading and global service centre, as well as the global metropolis where many international enterprises are based in. The latter is the first special economic zone in China and has been ranked the fourth place in respect of economic gross in China, inferior to Shanghai, Beijing and Guangzhou for years. Both are important container ports in the world, while lacing mineral resources (see Table 1).

Table 1: Introduction to Shenzhen and Hong Kong

\begin{tabular}{lcccc}
\hline & Area $\left(\mathbf{k m}^{\mathbf{2}}\right)$ & Population & $\begin{array}{c}\text { Gross Domestic } \\
\text { Products } \\
\text { (millions of RMB) }\end{array}$ & $\begin{array}{c}\text { GDP per capital, } \\
\text { current prices } \\
\text { (RMB) }\end{array}$ \\
\hline Shenzhen & 1991.64 & $13,026,600$ & $24,221.98$ & $202,198.00$ \\
Hong Kong & 1104.00 & $7,450,000$ & $24,000.98$ & $322,120.00$ \\
\hline
\end{tabular}

Data Sources: Shenzhen Statistics Bureau, WMF

The cooperation between Hong Kong and Shenzhen could be traced back to the end of 1970s, when reforming and opening-up in the Mainland China had just began. Shenzhen Special Economic Zone was entitled to several special policy preferences, and the enterprises from Hong Kong started moving their factories to the north. After that Shenzhen became a manufacturing base by using its strengths like the low-cost land and labor, and had been selling goods to the rest of the world through its springboard - Hong Kong. This "win-win" strategy gradually formed the "Shops in Front and Factories Behind" mode. In 2018, the total output value of Hong Kong was HKD1.80 trillion, and the total value of goods exported to Hong Kong from Shenzhen exceeded USD187 billion, accounting for $35 \%$ of the total value in Guangdong Province, and $38 \%$ of the import value in Hong Kong (the majority of them were distributed to the world through Hong Kong). However, there was little value of the goods imported into Guangdong through Hong Kong-- only USD6.20 billion, accounting for $1.40 \%$ of the total export value in Hong Kong and only $1.60 \%$ of the import value in Guangdong Province. Under the strategy of enlarging domestic demand, proposed by the central government, Shenzhen will be a potential export market for Hong Kong. 
Mainland China is also the largest foreign investment destination for Hong Kong, and Shenzhen is the most important investment place in the Mainland China for the enterprises from Hong Kong. By the end of 2018, 115,494.00 Hong Kong invested projects were approved in Shenzhen City, and HKD1,108.20 billion of direct investment by Hong Kong investors were utilized, accounting for $61.30 \%$ of the total foreign capital. The economy in Shenzhen and Hong Kong is always interdependent, and Shenzhen is a significant base for bridging manufacture and export trade. Hong Kong is gradually transforming itself into an international financing center, integrating such professional services as modern accounting, logistics, marketing, bank financing and more from its previous manufacturing center of the light industry. It could be argued that Hong Kong and Shenzhen have satisfied their own demands and benefited each other in the past 40 years of cooperation.

The economic trade cooperation between Shenzhen and Hong Kong has been seriously challenged in recent years. First, the operation of market economy is increasingly mature in China after over 40 years of reforming and opening-up, and some preferential policies specifically for Shenzhen have been granted to more individual provinces and cities. Shenzhen attracted less foreign capital than Jiangsu, etc. In addition, the "Shops in Front and Factories Behind" mode has been mostly adopted in extensive production. With the increase in land and labor costs in Pearl River Delta, Shenzhen faces challenges in this respect. Cheaper cost competition in the Northern provinces, as well as unstable global economy, impose a large stress on this highly foreign trade relying city.

With the increasing pressure resulting from economic development, and industrial transformation and upgrading, Guangdong government proposed a strategy of “vacating cage to change bird” (騰籠換鳥), or “double-transfer” in 2007. Specifically, industries with intensive labor, high energy consumption, high water consumption and high pollution have been transferred from Shenzhen to the eastern and western wings and mountain areas of northern Guangdong. Some labor forces have been also transferred to local places. All these have brought obvious pressures to Shenzhen, the role of the industrial manufacturing base obviously has not satisfied Shenzhen, and it is urgently needed to transform into high added value industries. Therefore, Qianhai is an important pilot area for Shenzhen to expand the modern logistics, professional service and finance industry.

\section{Development Problems of Qianhai Cooperation Zone}

Under the existing legal framework, Hong Kong and Shenzhen have developed much closer cooperation in several fields after the signing of CEPA. But effective cooperation in depth is still lacking, mainly in the following aspects:

\section{Economic Gap and Cooperative Awareness}

The governments of Hong Kong and Shenzhen lack of comprehensive cooperative awareness in respect of governance thinking, due to differences in political, economic and social factors. Hong Kong and Shenzhen have their natural relations of geographical location and population, and thus have achieved certain results through cooperation in the fields of industry, infrastructures, environment protection and etc. However, as two core cities at the east bank of the Pearl River Estuary, there's no 
clear industrial cooperation division, and the industrial competition is more than cooperation. The long-term regional development gap between Hong Kong and Shenzhen is not only one of the major problems in their economic and social development, but also a core issue to be solved in implementing regional synergized development strategy. Based on their respective interests, the governments of Hong Kong and Shenzhen act in their own ways, lacking regional-level reviews, as well as coordination and communication at all levels. The industrial structures of Hong Kong and Shenzhen are self-contained, and no reasonable industrial division is formed between them, so the industrial value chain is broken and the regional economic interaction is poor. In their cooperation, Hong Kong is always in absolute advantage. The market mechanism enables economically developed cities to attract and gather a lot of human resources, technologies, capitals and so on, thus accelerating the development of central cities.

\section{Industry Superposition}

There is a serious superposition in respect of key industries in Hong Kong and Shenzhen, which could be seen in the case of Qianhai. The four industries developed in the Qianhai Cooperation Zone, finance, modern logistics, information service, S\&T service and other professional service, superpose with the pillar industries in Hong Kong (see Table 2), which makes some exports, scholars and the public to worry about the side-effects. On the one hand, as the development of Qianhai, the third industry in Hong Kong would be transferred to Shenzhen again, making the industry in Hong Kong vacant. In the long term, Hong Kong's economy will be seriously affected, and Hong Kong will continue to be marginalized. On the other hand, Hong Kong has stronger competitive advantages, a sound law system, developed S\&T information, free trade, international financing centre, and international standardization. Therefore, it is expected that Hong Kong will dominate externally and Shenzhen will dominate internally in respect of financing development. In summary, there is a competition between the Qianhai Cooperation Zone in Shenzhen and Hong Kong.

Table 2: Comparison of Development of Industries in Hong Kong and in the Qianhai Cooperation Zone, Shenzhen

\begin{tabular}{c|l|l}
\hline No. & Four Pillar Industries in Hong Kong & Four Industries of Qianhai \\
\hline $\mathbf{1}$ & Finance Service & Finance \\
$\mathbf{2}$ & Trade and Logistics & Modern Logistics \\
$\mathbf{3}$ & Tourism and Industry and Commerce Support & S\&T Information Service \\
$\mathbf{4}$ & Professional Service & Other Professional Service \\
\hline
\end{tabular}

Notes: collected by the authors

\section{Interests-Coordination Mechanism}

There is no effective interests-cooperation and coordination mechanism between Hong Kong and Shenzhen who each represents an independent administrative area. When making an initial decision, they will seek to maximize their own interests, which lead to a "join but not to cooperate" situation. Due to the absence of regional and overall action for a united target, it is difficult to build the coordinative development layout with their development staggered and advantages supplemented. Therefore, "seeking for local economic interests" becomes the basic contradiction and 
key problem affecting regional economic cooperation. Economic integration is based on integration of interests, and there is no true regional integration without interestsintegration. Only when the interests-coordination mechanism for regional economic development is established, the conflicting interests between the two regions can be effectively solved.

\section{Development of Qianhai Cooperation Zone from Prisoner's Dilemma to Cooperative Game}

\section{Game Theory}

The Game Theory, in nature, is to apply mathematics study on competition and cooperation (Stanford Encyclopedia of Philosophy, 2006). It is used to study how people make decisions and how they can achieve equilibrium when the behaviour of the decision-making body interacts directly. Games can be classified into Cooperative and Non-cooperative Games. Since the mid-1980s, Game Theory has been widely used in the fields of economics, palynology, international relations and public selection. It has penetrated into almost all economic analysis fields, and developed to be a part of mainstream economics. It is also an important part of the operations research. Until now, many scholars have been engaged in study of the Game Theory in many fields. (Zhang, 2004; Huang, Tsai \& Cheng, 2017; Madani, 2010; Hu, 2018).

A game consists four basic elements: (1) Player, the decision maker, each of whom makes decisions rationally; (2) Action, all decisions that the players can choose; (3) Payoffs, the rewards received by the participants according to the strategy combination selected by each player at the end of the game; (4) Information, the information each player knows when making decision. The core concept of the noncooperative game theory is Nash Equilibrium (NE). The equilibrium is a forecast of the competitors' strategies under a given competition environment. The NE, proposed by Nash (1950), is defined as a concept of game theory where the optimal outcome of a game is one where no player has an incentive to deviate from his or her chosen strategy after considering an opponent's choice.

\section{Development from Prisoner's Dilemma to Cooperative Game}

The Qianhai Cooperation Zone is planned, constructed and managed by governments. In the regional economic cooperation and competition, the local governments of Hong Kong and Shenzhen are the main interests of their respective jurisdiction, and in this study, they are personalized as rational economic people. In the decision-making process, the local governments always consider their own local interests first and then local public interests. So local governments always adopt competition and protection in the process of development of economy. Each local government is deemed as a game player whose strategic space can be chosen and be successive. Therefore, each player has infinite options. This study focuses on the strategies in the non-cooperative game theory and pure strategies. 


\section{Prisoner's Dilemma}

The Prisoner's Dilemma, raised by Tucker (1940), is used to discuss whether there are problems in the cooperation equilibrium. In a simple two-player game, cooperation between these two players may help them realize the optimal results, but the betrayal inducement exists at the beginning since betrayal can make himself more benefits. Individual players may either cooperate to sacrifice the short-term self-interest to obtain common interests or betray to sacrifice the common interests to seek selfinterest. The payoffs of individual players are determined by the strategies adopted by the opponents, but must be in line with the payoff structure.

In a game, we assume there are two local governments as the players: the governments of Hong Kong and Shenzhen. There are "Cooperative" and "Noncooperative" strategies in the investment of Qianhai Cooperation Zone, and their information is asymmetrical. The players formulate their own strategies which focus on maximal self-interest. Upon cooperation, both players open their markets and practice the fair competition and get their self-interest (R). When they do not cooperate, they adopt local protection and maintain their interests in their respective region (R-C). If one player chooses cooperation, but the other player is noncooperative and adopts local protection, as a result, the cooperative player will lose its market share due to the other's local protection $(\delta)$. If the local government protects its market, its revenues will be larger than costs $(\delta \mathrm{R}>\mathrm{C})$. In this way, we get the revenue matrix under individual strategic combination, as shown in Table 3 below. In the table, the columns stand for the strategic space of Shenzhen Government, with the first figures in each block is its revenue, and the rows represent the strategic space of Hong Kong Government with the second figure in each block its revenue.

Table 3: Analysis of Development Strategies of Hong Kong and Shenzhen Governments in the Qianhai Cooperation Zone

\begin{tabular}{|c|c|c|c|}
\hline \multirow{4}{*}{ 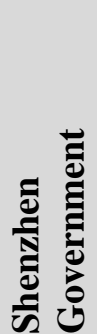 } & \multirow{4}{*}{$\begin{array}{l}\text { Cooperative } \\
\text { Non- } \\
\text { cooperative }\end{array}$} & \multicolumn{2}{|c|}{ Hong Kong Government } \\
\hline & & Cooperative & Non-cooperative \\
\hline & & $\mathrm{R}, \mathrm{R}$ & $(1-\delta) \mathrm{R},(1+\delta) \mathrm{R}-\mathrm{C}$ \\
\hline & & $(1+\delta) \mathrm{R}-\mathrm{C},(1-\delta) \mathrm{R}$ & $\mathrm{R}-\mathrm{C}, \mathrm{R}-\mathrm{C}$ \\
\hline
\end{tabular}

Obviously, in this game, there are two possible NEs: (Cooperative, Cooperative) and (Non-cooperative, Non-cooperative), under which both local governments will not take initiative to change their own strategy, with revenues of $(\mathrm{R}, \mathrm{R})$ and $(\mathrm{R}-\mathrm{C}, \mathrm{R}-\mathrm{C})$ respectively. But there is a big difference between their obtained payments levels. Based on the NE, the players establish their strategies under the assumption that the opponent will act according to its optimal strategy. In the case of cooperation, it will face the risk of losing the market share - $\delta$ when the opponent chooses "noncooperative". But in the case of non-cooperative, or local protection, the worst outcome is maintaining existing revenue level. The outcome of local protection adopted by the local governments is always better than cooperation $((1+\delta) \mathrm{R}-\mathrm{C}>\mathrm{R}$ or $\mathrm{R}>\mathrm{R}-\mathrm{C}$ ). Non-cooperative local protection strategy is the optimal strategy for both players, which is a kind of non-Pareto optimal equilibrium status. Therefore, (Noncooperative, Non-cooperative) forms the NE of this game. That is to say, for balanced 
benefits between the local governments, both players have no incentive to change this choice, thus making them to fall into the Prisoner's Dilemma.

If the game is only conducted once, both local governments will choose the low efficient and inferior strategy, and then the only equilibrium is that they both adopt the local protectionism, and it is hard to break through without external force. If this game is repeated, where communications are allowed and they trust each other, within the limited period $t$, it is always the Non-cooperative Game for the last sub-game, in which they will betray and trigger the Prisoner's Dilemma. We infer from this that the last one will be the Non-cooperative Game. For an infinite game, the NE point in the game is hard to determine. The Prisoner's Dilemma is a typical case of the Noncooperative Game, It reveals that if the local governments of Hong Kong and Shenzhen choose the most suitable strategies for themselves in the development of the Qianhai Cooperation Zone, in order to seek their maximum interests, the outcome will not be the ideal status of a "win-win" situation.

Considering that Hong Kong and Shenzhen governments are at different development stages and levels, and there are differences in geographical position, resources and administration systems, their competitiveness is different. With absolute advantages due to its international centre position, economic scale, administration system, talents, capital and innovation capacity, Hong Kong has stronger competitiveness in the Qianhai Cooperation Zone and can obtain a larger revenue share in the Qianhai cooperation. Correspondingly, Shenzhen is weaker in the competition and suffers revenue losses. Therefore, Shenzhen Government will tend to adopt the local protection strategy based on its own interest. However, once Shenzhen Government adopts the local protection strategy, the best strategy for Hong Kong Government will be the local protectionism too. Nevertheless, it is an inefficient strategy for the development of the Qianhai Cooperation Zone, and the Prisoner's Dilemma is triggered again.

\section{Cooperative Game}

In non-cooperative equilibrium, choosing the local protection strategy is an important path to realize the interests of local government at beginning. To break the lowefficient equilibrium of the local government competition strategy (Non-cooperative, Non-cooperative) and eliminate the Prisoner's Dilemma, the Central Government should participate in the game to change the revenue strategy of the local governments in the game.

Table 4: Analysis of Cooperative Development Strategies of Hong Kong and Shenzhen Governments in the Qianhai Cooperation Zone

\begin{tabular}{|c|c|c|c|}
\hline \multirow{4}{*}{ 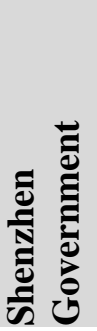 } & & \multicolumn{2}{|c|}{ Hong Kong Government } \\
\hline & & Cooperation & Non-cooperative \\
\hline & Cooperation & $\mathrm{R}, \mathrm{R}$ & $(1-\delta+\mathrm{m}) \mathrm{R},(1+\delta-\mathrm{m}) \mathrm{R}-\mathrm{C}$ \\
\hline & Non-cooperative & $(1+\delta-\mathrm{m}) \mathrm{R}-\mathrm{C},(1-\delta+\mathrm{m}) \mathrm{R}$ & $(1-\mathrm{m}) \mathrm{R}-\mathrm{C},(1-\mathrm{m}) \mathrm{R}-\mathrm{C}$ \\
\hline
\end{tabular}


In the analysis of the Table 3, the local government's initial choice is not conductive to the healthy development of Qianhai Cooperation Zone. The coordination of the Central Government is the key to break such path dependence. The Central Government provides incentive policies in the Qianhai Cooperation Zone agreement between Shenzhen and Hong Kong, improves the market rules, punishes local protectionism, and awards cooperative players (the punishment and award factors are $\mathrm{m}(0<\mathrm{m}<1))$. In this way, the revenues of the local governments in the game can be changed. If the punishment and award factor $m$ is big enough, and bigger than $\delta$, the revenues of the players are changed, as shown in Table 4 below. Then, the Noncooperative Strategy will not be equilibrium, and the only NE is (Cooperative, Cooperative).

If the game is repeated, it can be coordinated to realize the cooperation between the local governments. Because sound market order is a public good, creating of sound market order will be restricted by the transaction costs. The stronger local government can benefit more from the sound market order, and therefore has more impetus to improve the market order. Therefore, the player with a stronger competitiveness may pay a larger share of the transaction cost. For example, under the conditions listed in the Table 3, the Hong Kong Government, which is stronger in the game, decides that as long as the Shenzhen Government adopts the Cooperative strategy, it will compensate it for investment financing, fees, tax rate, technology, etc. The (Cooperative, Cooperative) will become the only NE. The Central Government can coordinate the acts of the local governments, act as an intermediate, or urge and help the local governments to establish a coordinative mechanism to reduce the coordination costs of local governments. The Central Government can also provide compensation to the weaker one, in order to maintain a sound market environment.

Hong Kong will show deep cooperation only when its economic development is protected. In the indefinite game, both players are required to pay attention to future revenues, and the restriction efficiency agreement shall be completed enough. The benefits from betrayal should be few, and the price of punishment should be greater than the revenues from betrayal. The development of Qianhai Cooperation Zone should be based on the (Cooperative, Cooperative) strategy as the equilibrium.

\section{Conclusion}

Cooperation zone, as a kind of economic park, has become the development pillar of the Chinese economy. Qianhai Cooperation Zone is the first cooperation zone between Mainland China and Hong Kong Government under the system of "One Country, Two Systems", which is a test of industrial development and a test of system and rules as well. As a cooperative demonstration zone for Shenzhen - Hong Kong modern service industry, it is upgraded to a national development strategy. However, because Hong Kong and Shenzhen Governments consider more local interests in respect of the development strategy of Qianhai Cooperation Zone, it will unavoidably cause inadequate construction and industry development of the Zone. This study analysed the competitive strategies of Hong Kong and Shenzhen in the development of Qianhai Cooperation Zone using the Game Theory. It concludes that the local governments will adopt local protectionism at the beginning in case of either equal competitiveness or different competitiveness, and local protectionism is a kind of low- 
efficient equilibrium and adverse to the long-term development. The maintenance of the market order by the Central Government as the highest management authority can promote the development to be a cooperative game and avoid the Prisoner's Dilemma. The Shenzhen Government can use its cost and policy advantages and the Hong Kong Government can rely upon its talents, technical and capital strengths, to cooperate to realize a transformation and "win-win" situations for both players.

Although we established the model for analysing two governments, the above conclusions will not be changed even if more than two governments participate in the game. Since the achievements of the local officials are embedded into the local economic interests, it is worthwhile to study in depth how local government officials influence government decision-making and the constraints of information costs and execution costs faced by central government's participation. Avoiding unnecessary competition between the local governments and achieving mutually beneficial cooperative strategy is a critical topic we are facing now.

\section{Implications for Asian Business Context}

Qianhai is a modern demonstration of the innovative cooperation between Guangdong and Hong Kong to create a modern service industry zone, it is upgraded to a national development strategy. However, because Hong Kong and Shenzhen Governments consider more local interests in respect of the development strategy of Qianhai Cooperation Zone, it will unavoidably cause inadequate construction and industry development of the Zone. This study analysed the competitive strategies of Hong Kong and Shenzhen in the development of Qianhai Cooperation Zone using the Game Theory. It concludes that the local governments will adopt local protectionism at the beginning in case of either equal competitiveness or different competitiveness, and local protectionism is a kind of low-efficient equilibrium and adverse to the long-term development. The coordination by the Central Government is a valid channel to shift from the Prisoner's Dilemma to the Cooperative Game for the development of Qianhai Cooperation Zone, thus providing references for the study on the development strategy of Cooperation Zone and Guangdong-Hong Kong-Macao Greater Bay Area.

\section{References}

Barney, J., (1991), "Firm resources and sustained competitive advantage", Journal of Management, vol. 17, no. 1, pp. 99-120.

Breton, A., (1998), Competitive governments: An economic theory of politics and public finance, Cambridge University Press, New York.

Cao, Q. L., (2009), "Shenzhen-Hong Kong financial cooperation: the concept, location and path", Studies on Hong Kong and Macao, vol. 30, no. 1, pp.1: 55-62.

Chan, T. G., \& Zhao, S. X. B., (2012), "Advanced producer services industries in Hong Kong and Shenzhen: Struggles towards integration", Asia Pacific Viewpoint, vol. 53, no. 1, pp. 70-85.

Chen, Q., Wang, C.H., \& Huang, S. Z., (2019), "Effects of organizational innovation and technological innovation capabilities on firm performance: Evidence from firms in China's Pearl River Delta”, Asia Pacific Business Review, vol. 4, no. 1, pp. 1-25. 
Christopher, M. Anderson, Y. A., Park, Y. T., Chang, C. H., Yang, T. W., \& Lee, M. L., (2012), "A game-theoretic analysis of competition among container port hubs: The case of Busan and Shanghai", Maritime Policy \& Management, vol. 35, no. 1, pp. 5-26.

Doommel, P. R., (1991), Intergovernmental relations in managing local government, Sage Publications, London.

Fan, G., Zhang, S. G., Yang, Z. W., Zhang, Y. S., \& Yuan, G. M., (1990), The outline of macroeconomic theory on public ownership, Shanghai Renmin Press, Shanghai.

Friedrich, A. H., (1960), The constitution of liberty, University of Chicago Press, Chicago.

Gu, S. Z., Cao, D. M., \& Yang, M., (2018), "The strategic thinking of building innovation ecosystem in Guangdong-Hong Kong-Macao Greater Bay Area", China Soft Science, vol. 4, no. 1, pp. 1-9.

He, X., Huang, S. Z., Chau, K.Y., Shen, H. W., \& Zhu, Y. L., (2019), "A study on the effect of environmental regulation on green innovation performance: A case of green manufacturing enterprises in Pearl River Delta in China", Foundation Environmental Protection \& Research, vol. 28, no. 107, pp.727-736.

Herrmann-Pillath, C., (2006), "Cultural species and institutional change in China", Journal of Economic, vol. XL, no. 3, pp. 539-574.

Hu, S. Q., (2018), "How to distribute the benefits in social cooperation? "The Clique Solution" of cooperative game surpassing Shapley value", Management World, vol. 34, no. 6, pp. 83-93.

Huang, S. Z., Chau, K. Y., Yin, F., \& Chen, Q., (2018), "The effect of the economic performance of a science park on air quality: An empirical study of Hsinchu science park in Taiwan", Applied Ecology and Environmental Research, vol. 16, no. 6, pp. 8105-8118.

Huang, S. Z., Tsai, H. T., \& Cheng, W. L., (2017), "Analysing coordinated development of logistics parks in China by hoteling model", Journal of Interdisciplinary Mathematics, vol. 20, no. 3, pp. 837-849.

Lee, L., \& Wong, P. K., (2009), "Firms' innovative performance: The mediating role of innovative collaborations", Munich Personal RePEc Archive, Paper No. 16193.

Li, H., Ding, S., \& Zhu, M. G., (2011), "On the Guangdong-Hong Kong Macao bay area: A preliminary review from the multi-centre cross -border cooperation perspective", Journal of Industrial Technological Economics, vol. 30, no. 8, pp. 3-9.

Lin, Y. F., \& Liu, P. L., (2004), "Local protectionism and market segmentation: A survey from a strategic perspective", China Centre for Economic Research, Working Paper Series, [2012-09-10].

Lo, W. L., Naidu, G. M., \& Yam, C. M., (2001), "Dynamic and responsive firm strategy: A case study of Hong Kong and China collaborations in Pearl River Delta", Journal of Global Marketing, vol. 14, no. 4, pp. 16-35.

Madani, K., (2010), "Game theory and water resources", Journal of Hydrology, vol. 381, no. 1, pp. 225-238.

Nash, J. F., (1950), “The bargaining problem”, Econometrica, vol. 18, no. 2, pp.155-162.

Penrose, E. T., (1959), The theory of the growth of the firm, Wiley, New York.

Porter, M. E., (1979), "How competitive forces shape strategy", Retrieved from https://hbr.o rg/1979/03/how-competitive-forces-shape-strategy

Shen, L. R., \& Dai, Y. C., (1990), "China has formed "princess economy" and its drawbacks and causes", Economic Research Journal, vol. 3, no. 1, pp. 12-19.

Song E. R., (2003), "Mainland and Hong Kong economy and the integration of a common fallacy analysis", Forward Position in Economics, vol. Z, no. 1, pp. 38-40.

Stanford Encyclopaedia of Philosophy, (2006), "Game theory", Retrieved from http://plato.sta nford.edu/entries/game-theory/>.

Tan, G., (2008), "About the development of cooperation between Shenzhen \& Hong Kong", Journal of the Central Institute of Socialism, vol. 152, no. 2, pp.79-83.

Tether, B. S., (2002), "Who co-operates for innovation, and why? An empirical analysis", Research Policy, vol. 31, no. 1, pp. 947-967. 
Wei, D. Z., (2007), "Shenzhen-Hong Kong: A super-giant metropolis: Its formation mechanism and strategic value", Journal of Shenzhen University (Humanities \& Social Sciences), vol. 24, no. 5, pp. 21-26.

Yang, X. Y., (2013), "Qianhai positioning "double springboard" Hong Kong worry marginalized", Retrieved from http://www.eeo.com.cn/eeo/jjgcb/2010/09/06/179892.sh tml.

Zhang, W. Y., (2004), "Game theory and information economics", Shanghai People's Publishing House, Shanghai.

Zhou, L. A., (2004), The incentive and cooperation of government officials in the political tournaments: An interpretation of the prolonged local protectionism and duplicative investments in China", Economic Research Journal, vol. 6, no. 1, pp.33-40.

Zhu, C. C., \& Gu, L. B., (2007), "Game analysis of competition strategy selection by local governments", Journal of Hebei University of Economics and Trade, vol. 28, no. 1, pp. $11-15$. 